\title{
Effect of post-annealing on structural and optical properties, and elemental distribution in heavy Eu-implanted $\mathrm{ZnO}$ thin films
}

\author{
Isao SAKAGUCHI, ${ }^{\dagger}$ Takeshi OHGAKI, ${ }^{*}$ Yutaka ADACHI, Shunichi HISHITA, ${ }^{*}$ \\ Naoki OHASHI and Hajime HANEDA* \\ Optronic Materials Center, National Institute for Materials Science, 1-1 Namiki, Tsukuba, Ibaraki 305-0044 \\ *Sensor Materials Center, National Institute for Materials Science, 1-1 Namiki, Tsukuba, Ibaraki 305-0044
}

\begin{abstract}
The effect of post-annealing on $\mathrm{ZnO}$ thin films implanted with $\mathrm{Eu}$ at $1 \times 10^{17} \mathrm{ions} / \mathrm{cm}^{2}$ was studied to characterize the structural and luminescent properties, and the distribution of $\mathrm{Eu}$ in thin films. After post-annealing at $600^{\circ} \mathrm{C}$, the broadening of the $\mathrm{ZnO}(002)$ diffraction peak was the same as that of the as-implanted sample. The sample showed orange luminescence due to $\mathrm{Eu}^{3+}$. After post-annealing at $900^{\circ} \mathrm{C}$, a sharp diffraction peak of $\mathrm{ZnO}(002)$ was observed. The orange luminescence due to $\mathrm{Eu}^{3+}$ had disappeared, and instead, the intense luminescence of the band-edge of $\mathrm{ZnO}$ was observed in the sample. Ion images of $\mathrm{Zn}$ and Eu indicated that the Eu separated from the $\mathrm{ZnO}$ during the post-annealing. It is thought that the difference in luminescence is due to the separation of $\mathrm{Eu}$ from $\mathrm{ZnO}$.
\end{abstract}

(02010 The Ceramic Society of Japan. All rights reserved.

Key-words : Luminescence, Ion implantation, Chemical vapor deposition, Secondary ion mass spectrometry

[Received June 2, 2010; Accepted July 15, 2010]

\section{Introduction}

Ion implantation plays an important role in the semiconductor field, and has been applied to oxide materials as a doping and surface modification method, as this technique offers high repeatability. Recently, a new method of producing a dose library for implantation has been developed. ${ }^{1)}$ The above approaches are useful in the scientific and technological fields because determining the dose library of implants in the substrate makes it possible to suppress unintentional factors introduced by contamination during annealing. We utilized the above method to study the optical properties of $\mathrm{ZnO}^{2)}$ because $\mathrm{ZnO}$ is considered to be a promising luminescent material using low-energy electron beam irradiation. ${ }^{3)} \mathrm{ZnO}$ shows luminescence in the visible region due to several origins: the transition from shallow donors to deep acceptors; ${ }^{4)}$ a singly charged oxygen vacancy; ${ }^{5)}$ and $\mathrm{Cu}$ phosphor. ${ }^{6)}$ In order to obtain other luminescence colors, rare-earth elements such as $\mathrm{Eu}$ and $\mathrm{Tb}$ are well known as a phosphor for blue, green, and orange luminescence, although the luminescence color also depends on the ionic state of the materials. ${ }^{7), 8)}$ It is well known that $\mathrm{Eu}^{3+}$ is a phosphor for producing orange luminescence. The luminescence by $\mathrm{Eu}^{3+}$ was observed in $\mathrm{ZnO}^{9)}$ and $\mathrm{GaN}^{10)}$ Recently, we showed the orange luminescence of $\mathrm{Eu}^{3+}$ in $\mathrm{ZnO}$ thin film implanted with $\mathrm{Eu}$, and determined the optimal dose of $\mathrm{Eu}$ for intense luminescence. ${ }^{11)}$ However, the $\mathrm{ZnO}$ thin films implanted with Eu were not characterized in terms of surface morphology, crystallinity, and $\mathrm{Eu}$ distribution. In the previous paper, it was suggested as additional evidence that the Eu-related luminescence disappeared by increasing the annealing temperature. In this paper, we report the effect of annealing temperature on the structure and optical properties and the elemental distribution in thin films and explain the reason for the disappearance of the Eu-related luminescence.

Corresponding author: I. Sakaguchi; E-mail: SAKAGUCHI. Isao@nims.go.jp

\section{Experimental procedure}

$\mathrm{ZnO}$ thin films on Si substrates were synthesized by electron cyclotron resonance (ECR)-assisted chemical vapor deposition (CVD). The reaction chamber containing the ECR source was pumped using a turbo-molecular pump to $2 \times 10^{-8}$ Torr. The $\mathrm{Zn}$ source was zinc acetylacetonate $\left[\mathrm{Zn}\left(\mathrm{CH}_{3} \mathrm{COCHCOCH}_{3}\right)_{2}\right.$ : $\left.\mathrm{Zn}(\mathrm{acac})_{2}\right]$, which was vaporized at $90^{\circ} \mathrm{C}$ and transferred to the reaction chamber at an $\mathrm{H}_{2}$ gas flow of 5 standard cubic centimeters per minute (sccm). The gas containing the $\mathrm{Zn}(\mathrm{acac})_{2}$ vapor was blown out to the substrate using a ring injector. The substrate temperature was fixed at $600^{\circ} \mathrm{C}$ during the deposition.

After thin film synthesis, Eu ion implantation (accelerating voltage of $150 \mathrm{keV}$ and dose of $1 \times 10^{17} \mathrm{ions} / \mathrm{cm}^{2}$ ) was carried out using a modified ion implantation system. After the $\mathrm{Eu}$ implantation, the $\mathrm{ZnO}$ thin film implanted with $\mathrm{Eu}(\mathrm{ZnO}: \mathrm{Eu})$ was annealed at 600 and $900^{\circ} \mathrm{C}$ for 10 and $40 \mathrm{~min}$ in air atmosphere using an infrared furnace.

The thin films were characterized ex situ by several techniques. The surface morphology of $\mathrm{ZnO}$ thin films was examined by atomic force microscopy (AFM). The structure of the films was studied by X-ray diffraction (XRD), employing an X'pert diffractometer (Panalytical Co. Ltd., Almelo, Netherlands). Room-temperature photoluminescence (RT-PL, ACCENT Technology Co. Ltd., rpm-2000) was measured using laser irradiation $(\lambda=266 \mathrm{~nm})$. Finally, the elemental distribution of $\mathrm{Zn}, \mathrm{Eu}$, and impurities in the $\mathrm{ZnO}$ films were analyzed by means of secondary ion mass spectroscopy (SIMS, Cameca, NanoSIMS 50).

\section{Results and discussion}

Figure 1 shows AFM images of several $\mathrm{ZnO}$ thin films, and reveals that the Eu implantation and post-annealing are effective in changing the surface morphology. It is obvious that the asdeposited thin film in Fig. 1a was covered with grains of about $500 \mathrm{~nm}$ in diameter. The following images indicate the effect of Eu implantation and the post-annealing on the surface morphol- 

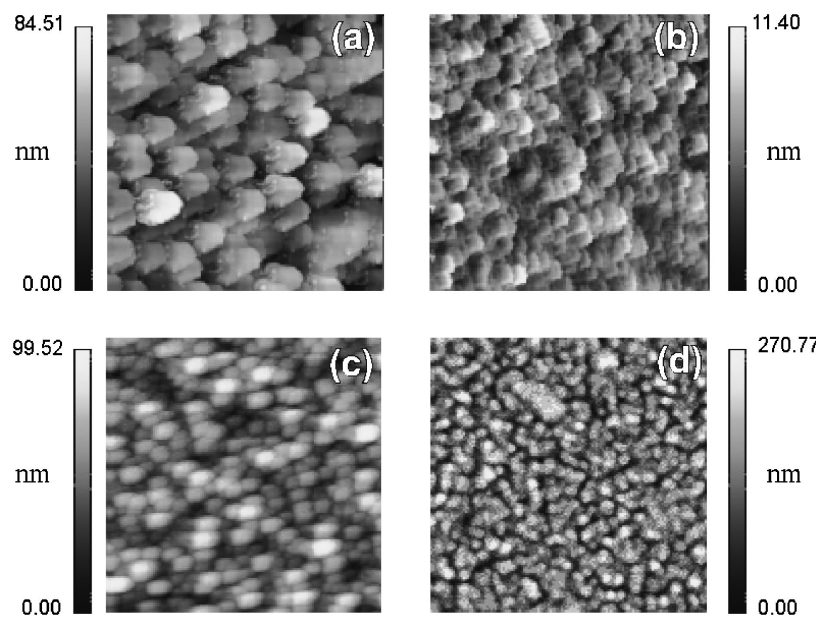

Fig. 1. AFM images of $\mathrm{ZnO}$ thin films: (a) as-deposited $\mathrm{ZnO}$, (b) as-implanted $\mathrm{ZnO}$ thin film, (c): $\mathrm{ZnO}: \mathrm{Eu}$ annealed at $600^{\circ} \mathrm{C}$, (d): $\mathrm{ZnO}: \mathrm{Eu}$ annealed at $900^{\circ} \mathrm{C}$. Scanning area of all images is $5 \times 5 \mu \mathrm{m}^{2}$.

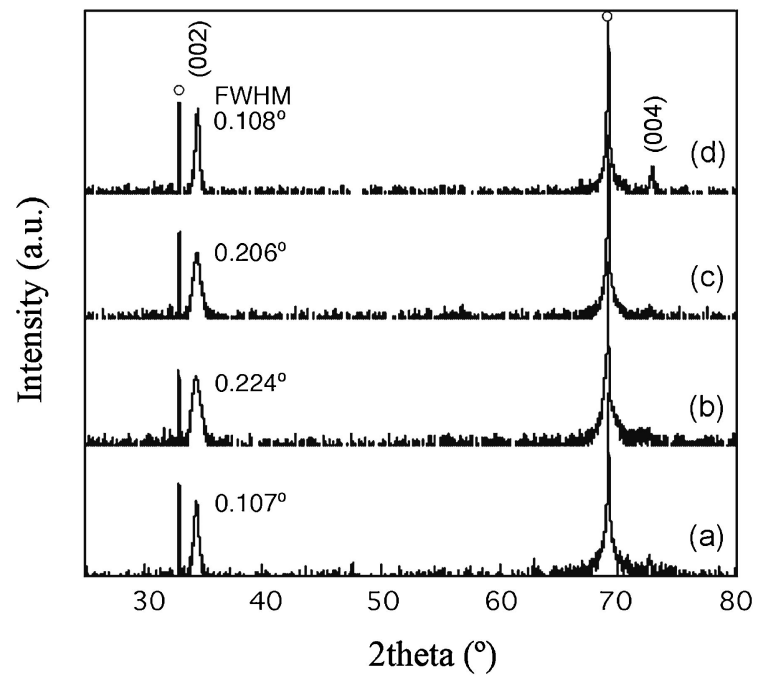

Fig. 2. XRD patterns of $\mathrm{ZnO}$ thin films: (a) as-deposited $\mathrm{ZnO}$, (b) as-implanted $\mathrm{ZnO}$ thin film, (c): $\mathrm{ZnO}: \mathrm{Eu}$ annealed at $600^{\circ} \mathrm{C}$, (d): $\mathrm{ZnO}: \mathrm{Eu}$ annealed at $900^{\circ} \mathrm{C}$. Open circles show the peaks of the substrate. The FWHM of $\mathrm{ZnO}(002)$ peaks are also shown in the figure.

ogy. Figure $1 \mathrm{~b}$ indicates the surface of the as-implanted $\mathrm{ZnO}: \mathrm{Eu}$. This image shows that the density of the thin film changed and the smoothness of the surface improved. The $\mathrm{ZnO}: \mathrm{Eu}$ annealed at $600^{\circ} \mathrm{C}$ shown in Fig. 1c shows quite a different surface morphology: round grains with a size of about $300 \mathrm{~nm}$ were observed. Figure 1d shows the result of $\mathrm{ZnO}: \mathrm{Eu}$ annealed at $900^{\circ} \mathrm{C}$. The grain size is obviously smaller than those of $\mathrm{ZnO}: \mathrm{Eu}$ annealed at $600^{\circ} \mathrm{C}$. Because of this, the surface smoothness has been lost. From the above, the post-annealing causes a significant change in the surface morphology.

Figure 2 shows XRD patterns of several $\mathrm{ZnO}$ thin films. All diffraction peaks were assigned as the $\mathrm{ZnO}$ and $\mathrm{Si}$ substrate. The diffraction peak corresponding to $\mathrm{ZnO}(002)$ is observed in all thin films, which is evident in $c$-axis oriented $\mathrm{ZnO}$ thin films. The $\mathrm{Eu}$ implantation causes the broadening of the $\mathrm{ZnO}(002)$ peak: the full width half maximum (FWHM) of $\mathrm{ZnO}(002)$ peak in the as-deposited (a) and as-implanted sample (b) is 0.107 and $0.224^{\circ}$, respectively. After the annealing at $600^{\circ} \mathrm{C}$, the FWHM of $\mathrm{ZnO}(002)$ peak is $0.206^{\circ}$. The $\mathrm{ZnO}: \mathrm{Eu}$ annealed at $600^{\circ} \mathrm{C}$

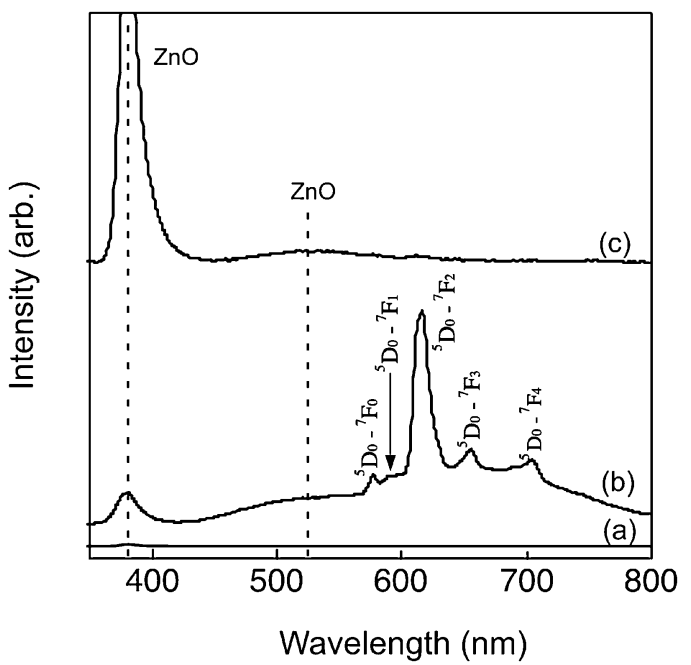

Fig. 3. Room-temperature photoluminescence spectra of $\mathrm{ZnO}$ thin films: (a) $\mathrm{ZnO}: \mathrm{Eu}$ as-implanted, (b) $\mathrm{ZnO}: \mathrm{Eu}$ annealed at $600^{\circ} \mathrm{C}$, (c) $\mathrm{ZnO}: \mathrm{Eu}$ annealed at $900^{\circ} \mathrm{C}$. The dashed lines indicated the luminescence centers of $\mathrm{ZnO}$.

contains the defects introduced into the lattice by Eu implantation. The $\mathrm{ZnO}(002)$ peak in the samples of as-deposited (a), as-implanted (b) and annealed at $600^{\circ} \mathrm{C}$ (c) are at $34.425,34.404$, and $34.466^{\circ}$, respectively. The XRD pattern of $\mathrm{ZnO}: \mathrm{Eu}$ annealed at $900^{\circ} \mathrm{C}$ was shown in spectrum (d). This shows the following feature: the FWHM of $\mathrm{ZnO}(002)$ peak of $0.108^{\circ}$ and the shift of $\mathrm{ZnO}(002)$ peak to $34.536^{\circ}$ and the appearance of the weak (004) peak. The above features imply that the crystal quality of $\mathrm{ZnO}: \mathrm{Eu}$ thin film recovered by a sufficient reaction during the postannealing temperature of $900^{\circ} \mathrm{C}$. Additional peaks, such as due to Eu-related materials, were not observed in the Eu implanted and post-annealed thin films.

Figure 3 shows the RT-PL spectra obtained from the $\mathrm{ZnO}: \mathrm{Eu}$ samples. Spectrum (a) was obtained in the as-implanted $\mathrm{ZnO}: \mathrm{Eu}$ thin film. The luminescence was not observed. Such results were certainly obtained in the as-implanted $\mathrm{ZnO}$ samples. ${ }^{2)}$ The reason is thought to be that the defects, such as dangling bonds, point defects, and dislocations, introduced by the ion implantation act as non-radiative defects in as-implanted $\mathrm{ZnO}$. In our studies, the luminescence property of the implanted $\mathrm{ZnO}$ could be obtained after post-annealing. ${ }^{2), 11)}$ The broadening of the $\mathrm{ZnO}(002)$ peak reflects the damage as well as the implants introduced by the ion implantation. In Fig. 2, the broadening of the $\mathrm{ZnO}(002)$ peak shows the maximum value in as-implanted $\mathrm{ZnO}: \mathrm{Eu}$, and decreases with increasing post-annealing temperatures. This supports the above consideration. In $\mathrm{ZnO}: \mathrm{Eu}$ annealed at $600^{\circ} \mathrm{C}$, spectrum (b) were characterized by the sharp luminescence lines in the wavelength range of $580-706 \mathrm{~nm}$, originating from the $\mathrm{Eu}^{3+}{ }^{3)}$ ) The main peak of $\mathrm{Eu}^{3+}$ at the $618 \mathrm{~nm}-$ wavelength and weak peaks at 580, 592, 657, and $706 \mathrm{~nm}-$ wavelengths were observed. The assignment of these peaks is shown in the figure. Additionally, weak luminescence peaks at 380 and about $530 \mathrm{~nm}$-wavelength originating from the $\mathrm{ZnO}$ were also observed. Spectrum (c) obtained in $\mathrm{ZnO}: \mathrm{Eu}$ annealed at $900^{\circ} \mathrm{C}$ shows that the intense luminescence of band-edge emission at the $380 \mathrm{~nm}$-wavelength of $\mathrm{ZnO}$ is the main contribution in the spectrum, which is evidence of the recovery of crystal quality. The luminescence originating from $\mathrm{Eu}^{3+}$ disappeared. Additionally, a weak, broad peak around the $530 \mathrm{~nm}$-wavelength was also observed. 


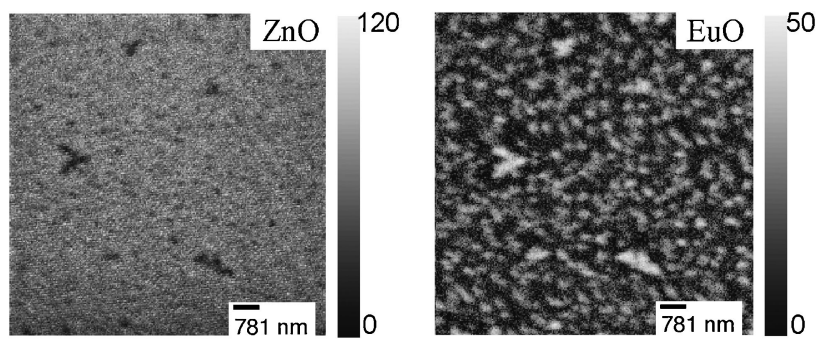

Fig. 4. Secondary ion images obtained in $\mathrm{ZnO}: \mathrm{Eu}$ annealed at $900^{\circ} \mathrm{C}$. The detected ions are also shown in the figure.

In $\mathrm{ZnO}: \mathrm{Eu}$ annealed at $600^{\circ} \mathrm{C}$, the degree of broadening of $\mathrm{ZnO}(002)$ peak is larger than those in the as-deposited and the annealed sample at $900^{\circ} \mathrm{C}$ in Fig. 2. The broadening of $\mathrm{ZnO}(002)$ diffraction peak is evidence of $\mathrm{Eu}$ in the $\mathrm{ZnO}$ lattice. The surface morphology after the post-annealing changed in Fig. 1b and 1c. This sample shows the luminescence peaks originated from $\mathrm{Eu}^{3+}$ and $\mathrm{ZnO}$ in Fig. 3a. From above results, the Eu diffused through the implantation damage and occupied the active site to appear as luminescence in the $\mathrm{ZnO}$ lattice. On the other hand, in the $\mathrm{ZnO}: \mathrm{Eu}$ thin film annealed at $900^{\circ} \mathrm{C}$, significantly different results were obtained compared with those of $\mathrm{ZnO}: \mathrm{Eu}$ annealed at $600^{\circ} \mathrm{C}$. The surface morphology indicates the changes to the rough surface in Fig. 1d. $\mathrm{ZnO}: \mathrm{Eu}$ thin film annealed at $900^{\circ} \mathrm{C}$ shows that the improvement of the broadening and shift to the high angle of the $\mathrm{ZnO}(002)$ peak was observed in Fig. 2. The luminescence due to $\mathrm{Eu}^{3+}$ disappeared, and the intense luminescence of band-edge of $\mathrm{ZnO}$ was observed. However, there is no evidence of $\mathrm{Eu}$ in the thin films. In order to show evidence of $\mathrm{Eu}$ in the thin film, we carried out measurements of the high-resolution ion image using a SIMS. Figure 4 presents the scanning ion images of $\mathrm{Zn}$ and $\mathrm{Eu}$ obtained from the $\mathrm{ZnO}: \mathrm{Eu}$ annealed at $900^{\circ} \mathrm{C}$. These reveal the heterogeneous distribution of $\mathrm{Zn}$ and Eu intensities in the images. The high intensity regions of Eu shown as arrows in Fig. $4 \mathrm{~b}$ are observed as the low intensity regions of $\mathrm{Zn}$ in Fig. 4a, indicating that the Eu separates from $\mathrm{ZnO}$ during the annealing. From Fig. 4, the grain size of $\mathrm{Eu}$ related phases were estimated to be about $200 \mathrm{~nm}$, which is in good agreement with those in Fig. 1d. The diffraction peak related with $\mathrm{Eu}$ was not detected, indicating that Eu related phases seem to be random orientations and/or amorphous. Here, after the Eu implantation of the dose of $1 \times 10^{17}$ ions $/ \mathrm{cm}^{2}, \mathrm{ZnO}$ thin film becomes metallic. The post-annealing causes reactions such as the oxidation of $\mathrm{Eu}$ and separation from the $\mathrm{ZnO}$ lattice. The rate of reaction depends on the temperature. In particular, considering the melting temperature of Eu metal (Tmp. = $822^{\circ} \mathrm{C}$ ), it is considered that the results in $\mathrm{ZnO}: \mathrm{Eu}$ annealed at $900^{\circ} \mathrm{C}$ are caused by the partial melting of a large amount of $\mathrm{Eu}$ in the $\mathrm{ZnO}$ thin film.

\section{Conclusions}

$\mathrm{ZnO}$ thin films were grown on $\mathrm{Si}$ substrate by ECR-assisted chemical vapor deposition. The thin film was then used as the substrate for heavy $\mathrm{Eu}$ implantation (accelerating voltage of $150 \mathrm{keV}$ and dose of $1 \times 10^{17} \mathrm{ions} / \mathrm{cm}^{2}$ ). Eu implanted $\mathrm{ZnO}$ thin films were annealed at 600 and $900^{\circ} \mathrm{C}$. In the $\mathrm{ZnO}: \mathrm{Eu}$ sample annealed at $600^{\circ} \mathrm{C}$, luminescence due to $\mathrm{Eu}^{3+}$ was observed. On the other hand, the luminescence of $\mathrm{Eu}^{3+}$ disappeared in the $\mathrm{ZnO}: \mathrm{Eu}$ sample annealed at $900^{\circ} \mathrm{C}$. The difference in the luminescence of $\mathrm{Eu}^{3+}$ can be explained as resulting from the separation of $\mathrm{Eu}$ from $\mathrm{ZnO}$. The above results indicate that the temperature of the post-annealing is an important factor in incorporating $\mathrm{Eu}$ in the active sites in $\mathrm{ZnO}$.

Acknowledgements Part of this study was carried out in the International Center for Materials Nanoarchitectonics (MANA), NIMS, Japan, supported by a Grant-in-Aid from the World Premiere Research Center Initiative (WPI) Program from the Ministry of Education, Culture, Sports, Science and Technology (MEXT), Japan. This work was also supported in part by Grants-in-Aid for Scientific Research (A) (No. 20246007) from the Japan Society for the Promotion of Science.

\section{References}

1) Y. Sato, I. Sakaguchi, M. Suzuki and H. Haneda, Jpn. J. Appl. Phys., 42, 5867-5868 (2003).

2) I. Sakaguchi, S. Hishita and H. Haneda, Jpn. J. Appl. Phys., 43, 5562-5563 (2004).

3) C. H. Seager, N. A. Missert, D. R. Tallant and W. L. Warren, Ext. Abstr. 3rd Conf. Science and Technology of Display Phosphors, Huntington Beach, CA (1997) p. 275.

4) D. C. Reynolds, D. C. Look, B. Jogai and H. Morkoc, Solid State Commun., 101, 643-646 (1997).

5) K. Vanheusden, W. L. Warren, C. H. Seager, D. R. Tallant, J. A. Voigt and B. E. Gnade, J. Appl. Phys., 79, 7983-7990 (1996).

6) B. J. Pierce and R. L. Hengehold, J. Appl. Phys., 47, 644-651 (1976).

7) K. Aono, M. Iwaki and S. Namba, Nucl. Instrum. Methods Phys. Res. B, 32, 231-234 (1988).

8) K. Aono and M. Iwaki, Nucl. Instrum. Methods Phys. Res. B, 141, 518-522 (1998).

9) A. Ishizumi, Y. Taguchi, A. Yamamoto and Y. Kanemitsu, Thin Solid Films, 486, 50-52 (2005).

10) Y. Nakanishi, A. Wakahara, H. Okada, A. Yoshida, T. Ohshima, H. Itoh, S. Nakano, K. Saito and Y. T. Kim, Nucl. Instrum. Methods Phys. Res. B, 206, 1033-1036 (2003).

11) I. Sakaguchi, Y. Sato, H. Ryoken, S. Hishita, N. Ohashi and H. Haneda, Jpn. J. Appl. Phys., 44, L1289-L1292 (2005). 